\title{
Aplicação de dejeto líquido de suínos e manejo do solo na sucessão aveia/milho ${ }^{1}$
}

\author{
Marlo Adriano Bison Pinto ${ }^{2}$, Cristiano Fabbris ${ }^{2}$, \\ Claudir José Basso², Antônio Luis Santi², Eduardo Girotto ${ }^{3}$
}

\begin{abstract}
Swine slurry application and soil management on double-cropped oat/maize

The swine production in southern Brazil is concentrated in small farms that use residues as a nutrient source for crops of economic interest. This study aimed to evaluate the use of swine slurry associated with tillage systems on double-cropped oat/maize. The experiment was carried out in the 2009/2010 and 2010/2011 cropping seasons, in Taquaruçu do Sul, Rio Grande do Sul State, Brazil. The experimental design was randomized blocks in a factorial scheme, with four replications. Treatments consisted of the interaction of four swine slurry doses (no swine slurry, $20 \mathrm{~m}^{3} \mathrm{ha}^{-1}, 40 \mathrm{~m}^{3} \mathrm{ha}^{-1}$ and $80 \mathrm{~m}^{3} \mathrm{ha}^{-1}$ ) and mineral fertilization, in three tillage systems (no-tillage, chiseling and chiseling + disking). The swine slurry application on doublecropped oat/maize increased the dry matter and grain yield. The $80 \mathrm{~m}^{3} \mathrm{ha}^{-1}$ dose provided a response statistically similar to the mineral fertilization recommended for maize. The interaction between the $80 \mathrm{~m}^{3} \mathrm{ha}^{-1}$ dose and the immediate incorporation of slurry into the soil reduced $\mathrm{N}$ losses by ammonia volatilization, promoting a significant increase in maize grain yield, when grown on a clayish soil.
\end{abstract}

KEY-WORDS: Zea mays L.; Avena strigosa Schreb; Avena sativa $\mathrm{L}$.

\section{INTRODUÇÃO}

A produção brasileira de carne suína vem crescendo anualmente, buscando suprir a demanda interna e, principalmente, a do mercado externo, cada vez mais exigente, com relação à qualidade da matéria-prima e ao cuidado com a questão ambiental. Esta produção, concentrada na pequena propriedade rural (Ceretta et al. 2005), tem como consequência a geração e concentração de um grande volume de

\section{RESUMO}

A produção de suínos no Sul do Brasil concentra-se em pequenas propriedades rurais, que buscam o aproveitamento dos resíduos como fonte de nutrientes às culturas agrícolas de interesse econômico. Este trabalho objetivou avaliar o uso de dejeto líquido de suínos, associado a manejos de solo, na sucessão aveia/milho. O experimento foi conduzido nos anos agrícolas 2009/2010 e 2010/2011, em Taquaruçu do Sul (RS). O delineamento experimental foi de blocos ao acaso, em esquema fatorial, com quatro repetições. Os tratamentos consistiram da interação de doses de dejeto líquido de suínos (sem dejeto, $20 \mathrm{~m}^{3}$ ha $^{-1}, 40 \mathrm{~m}^{3}$ ha-1 e $80 \mathrm{~m}^{3} \mathrm{ha}^{-1}$ ) e adubação mineral, em três manejos de solo (plantio direto, escarificação e escarificação + gradagem). A aplicação de dejeto líquido de suínos na sucessão aveia/milho promoveu incrementos na produção de matéria seca e na produtividade de grãos. A dose de $80 \mathrm{~m}^{3}$ ha $^{-1}$ apresentou resposta estatisticamente igual à adubação mineral recomendada para o milho. A interação entre a dose de $80 \mathrm{~m}^{3} \mathrm{ha}^{-1}$ e a incorporação imediata do dejeto ao solo implicou na diminuição das perdas de $\mathrm{N}$ por volatilização de amônia, promovendo incremento significativo na produtividade de grãos de milho, quando cultivado em solo de textura argilosa.

PALAVRAS-CHAVES: Zea mays L.; Avena strigosa Schreb; Avena sativa L.

dejetos, os quais representam um risco, do ponto de vista ambiental, gerando a necessidade de se minimizar o impacto destes resíduos sobre o ambiente. Por isto, a utilização de dejeto líquido de suínos (DLS) como fonte de nutrientes, em áreas com lavoura e pastagem, apresenta-se como uma alternativa ao descarte deste resíduo (Ceretta et al. 2005, Assmann et al. 2009, Seidel et al. 2010).

O nitrogênio $(\mathrm{N})$ é o principal nutriente encontrado no DLS (Sánchez \& González 2005), sendo a

1. Trabalho recebido em ago./2013 e aceito para publicação em jun./2014 (nº registro: PAT 25759).

2. Universidade Federal de Santa Maria (UFSM), Centro de Educação Superior Norte do Rio Grande do Sul, Departamento de Ciências Agronômicas e Ambientais, Frederico Westphalen, RS, Brasil.E-mails: marlo.bison@gmail.com, cristianofabbris@yahoo.com.br, claudirbasso@gmail.com, santi_pratica@yahoo.com.br.

3. Instituto Federal de Educação, Ciência e Tecnologia do Rio Grande do Sul (IFRS), Campus Ibirubá, Ibirubá, RS, Brasil. E-mail: eduardo.girotto@ibiruba.ifrs.edu.br. 
proporção de N orgânico e mineral presentes no DLS muito dependente das condições de armazenamento, sistema criatório e lavagem das instalações. $\mathrm{Na}$ maioria das unidades de produção, os dejetos são armazenados na forma líquida, em condições de anaerobiose, caracterizando-se como resíduo com baixo teor de matéria seca e alto teor de $\mathrm{N}$ na forma amoniacal (40-70\% do $\mathrm{N}$ total) (Aita et. al. 2006).

Medeiros et al. (2007) concluíram que a aplicação de DLS $\left(180 \mathrm{~m}^{3} \mathrm{ha}^{-1}\right.$ ano $\left.^{-1}\right)$ fermentado ou in natura possibilitou uma produção de MS do capim-marandu (Brachiaria bizantha cv. Marandu) similar à obtida com adubo mineral. Na cultura do milho, Seidel et al. (2010) demonstraram que a aplicação de DLS, em doses de até $50 \mathrm{~m}^{3}$ ha-1, como adubação de base, foi estatisticamente igual à adubação química (NPK). Trabalhando com a sucessão aveia preta/milho/nabo forrageiro, Ceretta et al. (2005) observaram que a utilização de DLS incrementou a produção de matéria seca em todas as culturas da sucessão, nos dois anos de condução do experimento. Os mesmos autores ressaltaram que a maior eficiência técnica, para a produtividade de grãos de milho e para a produção de MS de aveia preta, ocorreu com doses muito altas de DLS (aproximadamente $85 \mathrm{~m}^{3} \mathrm{ha}^{-1}$ ), tornando evidente que, na tomada de decisão sobre doses de DLS, também devem ser levados em consideração aspectos operacionais, econômicos e ambientais.

No sistema de semeadura direta, a volatilização de amônia tem sido apontada como um importante caminho de perda de N do DLS (Gonzatto et al. 2013). Contudo, alguns trabalhos demonstram que a incorporação de DLS ao solo reduz, consideravelmente, esta perda (Giacomini \& Aita 2008, Giacomini et al. 2009).

Nesse sentido, os sistemas de manejo de solo também podem influenciar na dinâmica dos nutrientes adicionados via DLS, o que deve ser destacado, principalmente, em propriedades que realizam o preparo do solo para estabelecimento de culturas invernais.

Este trabalho objetivou avaliar a influência do DLS, associado aos manejos de solo plantio direto, escarificação e escarificação + gradagem, sobre a produção de biomassa e produtividade de grãos, na sucessão aveia/milho.

\section{MATERIAL E MÉTODOS}

O experimento foi conduzido nos anos agrícolas 2009/2010 e 2010/2011, no município de
Taquaruçu do Sul (RS), situado na região do Médio Alto Uruguai $\left(27^{\circ} 28^{\prime} \mathrm{S}, 53^{\circ} 26^{\prime} \mathrm{W}\right.$ e altitude média de $480 \mathrm{~m}$ ). O clima do local é subtropical úmido (Cfa), conforme classificação de Köppen (Moreno 1961). O solo deriva da decomposição de rochas basálticas, sendo classificado como Latossolo Vermelho aluminoférrico típico (Embrapa 2013). A precipitação pluvial diária, durante o desenvolvimento do milho, é demonstrada na Figura 1.

Antes da implantação do experimento, em virtude de a área ser manejada sob plantio direto consolidado, foi amostrada a camada de $0-10 \mathrm{~cm}$ do solo (CQFS RS/SC 2004), obtendo-se as seguintes características: $\mathrm{pH}$ em água $(1: 1)=5,7$; índice $\mathrm{SMP}=6,2$; argila $=450 \mathrm{~g} \mathrm{~kg}^{-1}$; matéria orgânica $=24 \mathrm{~g} \mathrm{~kg}^{-1}$; potássio $=0,17 \mathrm{cmol}_{\mathrm{c}} \mathrm{dm}^{-3}$; cálcio $=10,1 \mathrm{cmol}_{\mathrm{c}} \mathrm{dm}^{-3} ;$ magnésio $=3 \mathrm{cmol} \mathrm{dm}^{-3}$; alumínio $=0 \mathrm{cmol}_{\mathrm{c}} \mathrm{dm}^{-3}$; fósforo $($ Mehlich $)=2,2 \mathrm{mg} \mathrm{dm}^{-3}$; enxofre $=12 \mathrm{mg} \mathrm{dm}^{-3}$; e manganês $=27 \mathrm{mg} \mathrm{dm}^{-3}$.

O delineamento experimental foi em arranjo fatorial, em blocos ao acaso, com quatro repetições. Os tratamentos consistiram de quatro doses de DLS (sem DLS, $20 \mathrm{~m}^{3} \mathrm{ha}^{-1}, 40 \mathrm{~m}^{3} \mathrm{ha}^{-1}$ e $80 \mathrm{~m}^{3} \mathrm{ha}^{-1}$ ), costumeiramente utilizadas por produtores na região do estudo, um tratamento com adubação mineral (CQFS RS/SC 2004) e três manejos de solo: plantio direto, escarificação (profundidade de $0-28 \mathrm{~cm}$ ) e escarificação + gradagem, realizados somente antes da semeadura da aveia branca e aveia preta, sendo, posteriormente, a semeadura de milho realizada diretamente sobre a palhada de aveia. Anteriormente à instalação da primeira cobertura do solo, no inverno, a área estava sendo cultivada com soja. A área já se encontrava há 10 anos sob plantio direto, basicamente seguindo a sucessão trigo/aveia, no inverno, e soja, no verão.

O DLS foi proveniente de uma propriedade com armazenagem em lagoa de estabilização, próxima ao local do experimento. No tanque e antes da coleta deste resíduo, foi efetuada a homogeneização do dejeto com o próprio distribuidor. Para isto, por duas vezes consecutivas, foi efetuada a carga e descarga com pressão do equipamento, na lagoa de estabilização. Esta operação foi realizada a 1,5 m de profundidade, sendo, também esta a profundidade de coleta do DLS, logo após a segunda operação de carga e descarga do resíduo.

Próximo à área experimental, o DLS foi acondicionado em caixa de cimento amianto, com homogeneização constante durante todo o período de aplicação nas unidades experimentais, evitando-se a 

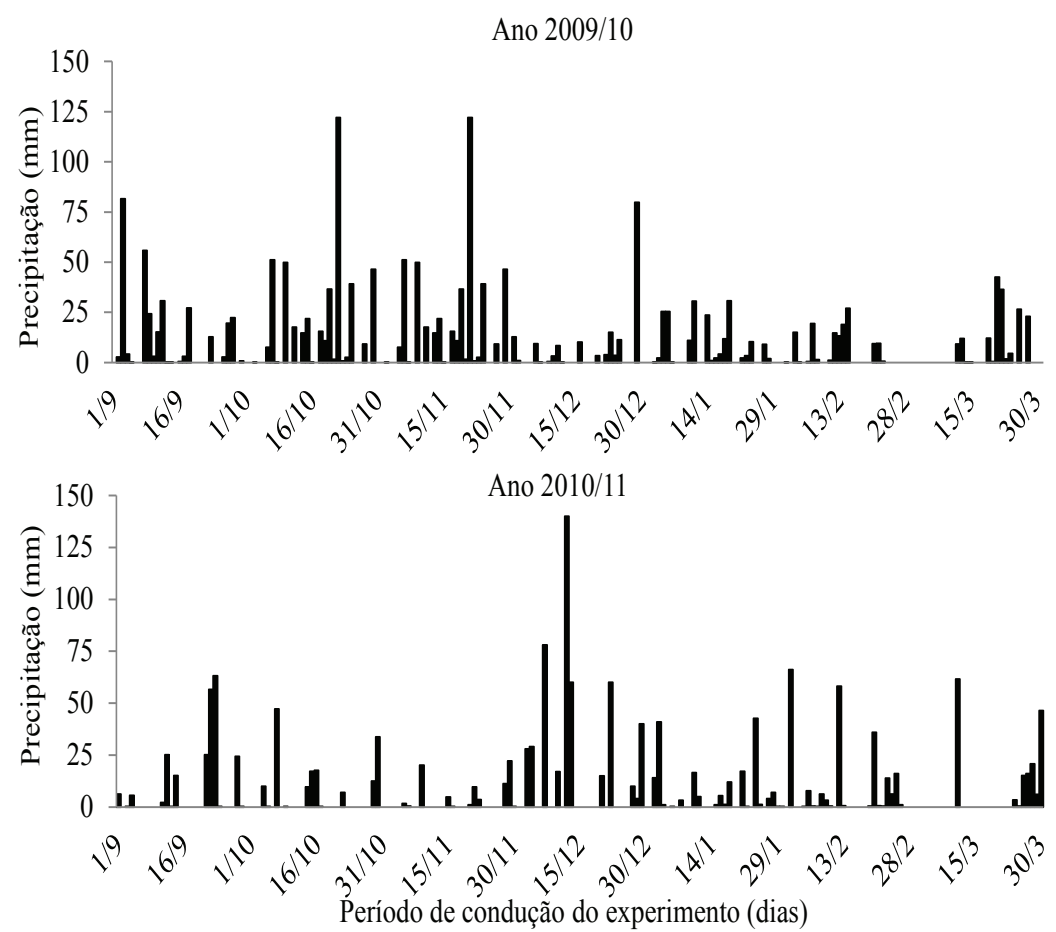

Figura 1. Precipitação pluviométrica diária registrada durante o desenvolvimento do milho, nos anos agrícolas 2009/2010 e 2010/2011. Dados obtidos na Estação Meteorológica de Frederico Westphalen (RS).

decantação da fração mais grosseira no fundo da caixa. Na área experimental, antes do início da aplicação de DLS nas parcelas, após boa homogeneização, foi coletada uma alíquota de DLS, a qual foi armazenada em refrigerador, para posterior análise em laboratório. A matéria seca dos dejetos foi determinada após a secagem do dejeto em estufa, a $65^{\circ} \mathrm{C}$, até peso constante. $\mathrm{O}$ teor de $\mathrm{N}$ total nos dejetos in natura foi avaliado conforme Aita \& Giacomini (2008). Os teores de $\mathrm{Pe} \mathrm{K}$ foram analisados no material seco, em estufa a $65^{\circ} \mathrm{C}$, após moagem (Tedesco et al. 1995), e o pH com o auxílio de pHmetro.

A composição química do DLS, assim como as quantidades de nutrientes adicionadas a cada dose aplicada (média das quatro aplicações), é apresentada na Tabela 1.

A aplicação de DLS foi realizada de forma manual, com a utilização de regadores, em dois momentos, em cada ano agrícola: antes da implantação da cultura de inverno (aveia) e antes da semeadura da cultura de verão (milho). A adubação mineral foi realizada apenas para a cultura do milho (CQFS RS/ SC 2004).

Em julho de 2009, foi realizada dessecação da área e, posteriormente, a demarcação da área
Tabela 1. Características químicas do dejeto líquido de suínos (DLS) e quantidades de nitrogênio, fósforo e potássio aplicados nas diferentes doses de DLS (média de quatro aplicações) (Taquaruçu do Sul, RS, 2011).

\begin{tabular}{|c|c|c|c|c|c|}
\hline $\begin{array}{l}\text { Dose de } \\
\text { DLS }\end{array}$ & $\begin{array}{l}\text { Matéria } \\
\text { seca }\end{array}$ & Nitrogênio & Fósforo & Potássio & $\mathrm{pH}$ \\
\hline \multirow{3}{*}{$\mathrm{m}^{3} \mathrm{ha}^{-1}$} & & $-\mathrm{gk}$ & & & \multirow{3}{*}{7,81} \\
\hline & 13,40 & 3,51 & 0,37 & 0,45 & \\
\hline & \multicolumn{4}{|c|}{ - $\mathrm{kg} \mathrm{ha}^{-1}$ adicionado } & \\
\hline 20 & 267,6 & 70,2 & 7,4 & 8,9 & - \\
\hline 40 & 535,3 & 140,4 & 14,8 & 17,8 & - \\
\hline 80 & $1.070,5$ & 280,8 & 29,6 & 35,6 & - \\
\hline
\end{tabular}

experimental. Com uma área experimental total de $1.257,6 \mathrm{~m}^{2}$, as dimensões das parcelas foram de

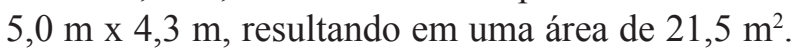
A semeadura da aveia branca foi realizada a lanço, no dia 25/07/2009, com densidade de $110 \mathrm{~kg}$ de sementes ha ${ }^{-1}$. Em 2010, foi utilizada aveia preta e a semeadura a lanço realizada no dia 05/05/2010, com densidade de $100 \mathrm{~kg}$ de sementes ha-1. $\mathrm{O}$ uso de aveia branca, no primeiro ano, deve-se ao fato de não se encontrar aveia preta no mercado local, a qual é muito procurada na região. Por ocasião do florescimento das plantas de aveia branca e aveia preta, foi amostrada 
uma área de $0,25 \mathrm{~m}^{2}$, para determinação da produção de matéria seca. Posteriormente, realizou-se a aplicação de glyphosate (720 $\left.\mathrm{g} \mathrm{ha}^{-1}\right)$, para dessecação da área destinada à implantação da cultura do milho.

A semeadura do milho, no ano agrícola 2009/2010, foi realizada no dia 05 de outubro, com o híbrido Pioneer 30B39Y ${ }^{\circledR}$, utilizado com duplo propósito (produção de silagem ou grãos). A semeadura mecânica foi realizada com espaçamento de $0,45 \mathrm{~m}$ entre as linhas e densidade de 70.000 plantas ha ${ }^{-1}$. Para o tratamento com adubação mineral, foram aplicados $363 \mathrm{~kg} \mathrm{ha}^{-1}$ da formulação $9(\mathrm{~N})-33\left(\mathrm{P}_{2} \mathrm{O}_{5}\right)$ $-12\left(\mathrm{~K}_{2} \mathrm{O}\right)$, no momento da semeadura, e $175 \mathrm{~kg} \mathrm{ha}^{-1}$ de $\mathrm{N}$ (fonte ureia - $450 \mathrm{~g} \mathrm{~kg}^{-1}$ de $\mathrm{N}$ ) em cobertura, quando as plantas se encontravam com cinco folhas expandidas.

No ano agrícola 2010/2011, o híbrido de milho utilizado foi o $2 \mathrm{~A} 250^{\circledR} \mathrm{HX}$ da Dow AgroSciences, com semeadura mecânica realizada no dia 10 de outubro, no espaçamento de $0,45 \mathrm{~m}$ ente as linhas e densidade de 60.000 plantas ha $\mathrm{h}^{-1}$. No tratamento com adubação mineral, foi utilizada a formulação 9-33-12, na dose de $340 \mathrm{~kg} \mathrm{ha}^{-1}$, e, ainda, $175 \mathrm{~kg} \mathrm{ha}^{-1}$ de $\mathrm{N} \mathrm{em}$ cobertura (fonte ureia), quando as plantas de milho apresentavam cinco folhas expandidas.

No pleno florescimento da cultura do milho, foram coletadas, aleatoriamente, cinco plantas das quatro linhas centrais de cada parcela, para a determinação da produção de matéria seca. A colheita para avaliação da produtividade de grãos foi realizada de forma manual, desconsiderando-se $0,5 \mathrm{~m}$ de cada lado da parcela, e a trilha com o auxílio de batedor tratorizado. Após a trilha, foi avaliada a umidade de cada amostra e o rendimento de grãos corrigido para $13 \%$ de umidade.

Os resultados foram submetidos à análise de variância. Nos casos de F significativo, foi realizada a comparação de médias por meio do teste Tukey \& Dunnett $(\mathrm{p}<0,05)$. Para o fator quantitativo, foi efetuada análise de regressão polinomial, utilizando-se o programa computacional SAS (SAS Institute 1999).

\section{RESULTADOS E DISCUSSÃO}

Com base no consumo relativo de água, para os estádios de desenvolvimento das culturas, observou-se ausência de défice hídrico, portanto, a disponibilidade de água, durante o cultivo, não foi fator limitante ao desenvolvimento e produtividade das culturas.

As doses de DLS e manejos de solo influenciaram, de forma significativa, as variáveis estudas. Comparando-se a produção de matéria seca da aveia branca e da aveia preta, entre os sistemas de manejo do solo, observou-se que, para a aveia branca, não houve diferenças significativas entre os manejos de solo (Tabela 2).

Já para a aveia preta, a maior produção de matéria seca foi observada no sistema de plantio direto $\left(5.400,6 \mathrm{~kg} \mathrm{ha}^{-1}\right)$, com incremento médio de $14 \%$, em relação à média dos outros dois manejos de solo. A falta de interação entre manejo do solo e doses de DLS pode indicar que a maior produção de matéria seca da cobertura de inverno sob plantio direto deve estar associada à permanência dos resíduos vegetais na superfície do solo, trazendo benefícios à conservação do solo e da água (Ralisch et al. 2008).

Para a produção de matéria seca do milho, no ano agrícola 2010/2011, houve diferença significativa entre os manejos de solo (Tabela 2), sendo menor a produção de matéria seca na parte aérea do milho sob plantio direto. Este resultado pode estar associado à resposta diferenciada dos híbridos utilizados, bem como às maiores perdas de $\mathrm{N}$, com aplicação do DLS

Tabela 2. Produção de matéria seca da aveia branca (2009/2010) e aveia preta (2010/2011) e da parte aérea do milho, em dois anos agrícolas, em função de diferentes manejos de solo (Taquaruçu do Sul, RS, 2011).

\begin{tabular}{crrr}
\hline \multirow{2}{*}{ Cobertura/cultura comercial } & \multicolumn{3}{c}{ Manejo do solo } \\
\cline { 2 - 3 } & Escarificação + gradagem & Escarificação & Plantio direto \\
\cline { 2 - 3 } Cobertura inverno & $1.366,5 \mathrm{a}^{1}$ & $1.537,3 \mathrm{a}$ \\
Aveia branca & $4.727,6 \mathrm{~b}$ & $1.353,5 \mathrm{a}$ & $5.400,6 \mathrm{a}$ \\
Aveia preta & & $4.744,4 \mathrm{~b}$ & $10.371,0 \mathrm{a}$ \\
Parte aérea milho & $9.816,3 \mathrm{a}$ & $\mathrm{kg} \mathrm{ha}^{-1}$ & $7.135,5 \mathrm{c}$ \\
$2009 / 2010$ & $8.944,4 \mathrm{a}$ & $9.961,5 \mathrm{a}$ & $7.943,2 \mathrm{~b}$ \\
$2010 / 2011$ & &
\end{tabular}

${ }^{1}$ Médias seguidas pela mesma letra, na linha, não diferem entre si, pelo teste Tukey $(\mathrm{p}<0,05)$. 
à superfície do solo sem revolvimento (Gonzatto et al. 2013). Segundo os mesmo autores, o N é um dos nutrientes encontrados em maior proporção no dejeto líquido de suínos. Na maioria dos casos, cerca de $50 \%$ deste $\mathrm{N}$ encontra-se na forma mineral, podendo ocorrer perdas de $\mathrm{N}$ por volatilização na forma de amônia $\left(\mathrm{NH}_{3}\right)$, que diminui o potencial fertilizante do dejeto. A incorporação imediata do dejeto, logo após aplicação no campo, diminuiu as perdas de $\mathrm{N}$ por volatilização de amônia, processo que é favorecido pela maior temperatura na superfície do solo, quando o mesmo é manejado sob plantio direto.

Para o ano agrícola 2009/2010, não houve diferença significativa entre os manejos de solo, corroborando o que foi observado por Borghi et al. (2007), os quais não verificaram diferenças na produção da matéria seca de milho, em função do manejo do solo (cultivo convencional, cultivo mínimo e plantio direto).

As doses de DLS incrementaram, de forma linear, a produção de matéria seca da aveia branca e da aveia preta, nos dois anos avaliados (Figura 2).

Os incrementos na produção de matéria seca, para o ano agrícola 2009/2010, foram de 76\%, 101\% e $185 \%$, respectivamente para as doses de $20 \mathrm{~m}^{3} \mathrm{ha}^{-1}$, $40 \mathrm{~m}^{3} \mathrm{ha}^{-1}$ e $80 \mathrm{~m}^{3} \mathrm{ha}^{-1}$, em relação ao tratamento sem DLS. Para cada $\mathrm{m}^{3}$ de DLS aplicado, os incrementos foram de $31 \mathrm{~kg} \mathrm{ha}^{-1}, 21 \mathrm{~kg} \mathrm{ha}^{-1}$ e $19 \mathrm{~kg} \mathrm{ha}^{-1}$, respectivamente para as doses de $20 \mathrm{~m}^{3} \mathrm{ha}^{-1}, 40 \mathrm{~m}^{3} \mathrm{ha}^{-1} \mathrm{e}$ $80 \mathrm{~m}^{3} \mathrm{ha}^{-1}$.

No segundo ano, os incrementos, em relação ao tratamento sem DLS, atingiram valores superiores $(62 \%, 122 \%$ e $248 \%$, respectivamente para as doses de $20 \mathrm{~m}^{3}$ ha $^{-1}, 40 \mathrm{~m}^{3} \mathrm{ha}^{-1}$ e $80 \mathrm{~m}^{3} \mathrm{ha}^{-1}$ ). Resultados semelhantes foram observados por Assmann et al. (2009), os quais verificaram resposta linear à aplicação de esterco líquido de suínos para doses de até $120 \mathrm{~m}^{3} \mathrm{ha}^{-1}$, em pastagem anual de inverno.

$\mathrm{O}$ atraso na semeadura da aveia branca, no ano agrícola 2009/2010, explica a baixa produção de matéria seca, quando comparada à aveia preta (Figura 2), que foi semeada mais precocemente, sendo maior o tempo de desenvolvimento vegetativo no campo. Soma-se a isto, também, um possível efeito residual das duas aplicações de DLS realizadas antes do estabelecimento da aveia preta, como observado por Cela et al. (2011), em trabalho de seis anos, na produção de trigo.

A produção de matéria seca da parte aérea do milho aumentou de forma linear, nos dois anos de

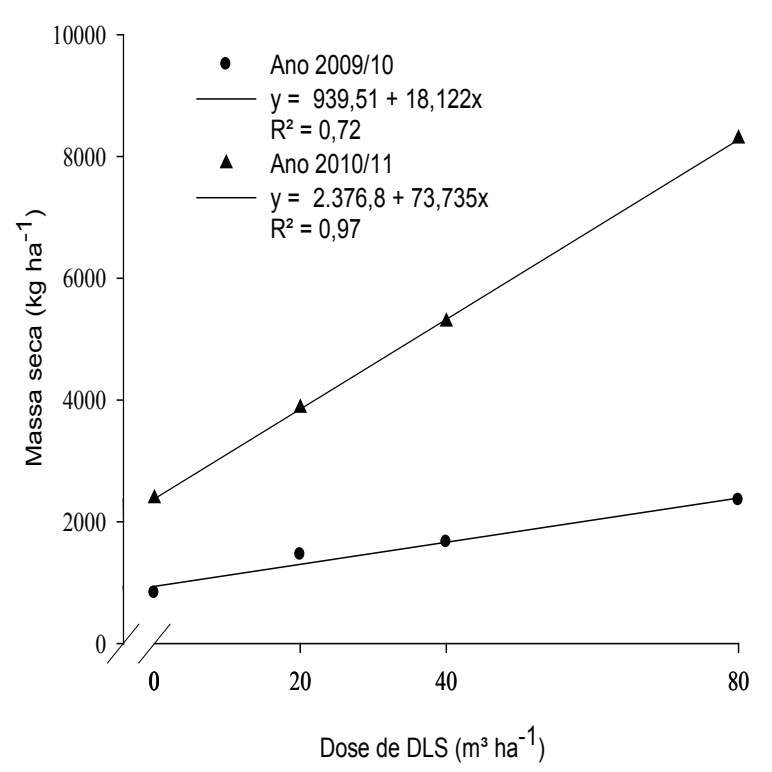

Figura 2. Produção de matéria seca de aveia branca (2009/2010) e aveia preta (2010/2011), em função de doses de dejeto líquido de suínos (DLS) (Taquaruçu do Sul, RS, 2011).

estudo, de acordo com o incremento nas doses de DLS (Figura 3).

As respostas, porém, foram diferentes entre os anos, o que pode ser justificado pelo fato de o híbrido utilizado no primeiro ano ser de maior estatura (híbrido duplo propósito), destinado à produção de silagem ou grãos. Com a aplicação de DLS, os incrementos na produção de matéria seca do milho, no ano agrícola 2009/2010, foram de $28 \%, 35 \%$ e $61 \%$ e, no ano agrícola $2010 / 2011$, de $53 \%, 65 \%$ e $130 \%$, respectivamente para as doses de $20 \mathrm{~m}^{3} \mathrm{ha}^{-1}, 40 \mathrm{~m}^{3} \mathrm{ha}^{-1}$ e $80 \mathrm{~m}^{3} \mathrm{ha}^{-1}$, quando comparados aos do tratamento sem DLS. Resposta positiva também foi observada por Ceretta et al. (2005), trabalhando com milho sob as mesmas doses de DLS do presente estudo.

Levando-se em consideração a produção média de matéria seca dos dois anos cultivados com milho, para cada $\mathrm{m}^{3}$ de DLS aplicado, o incremento foi de $119 \mathrm{~kg} \mathrm{ha}^{-1}, 69 \mathrm{~kg} \mathrm{ha}^{-1}$ e $67 \mathrm{~kg} \mathrm{ha}^{-1}$ de matéria seca, respectivamente para as doses de $20 \mathrm{~m}^{3} \mathrm{ha}^{-1}$, $40 \mathrm{~m}^{3}$ ha $^{-1}$ e $80 \mathrm{~m}^{3} \mathrm{ha}^{-1}$, mostrando redução na taxa de produção de matéria seca, conforme o aumento das doses.

A comparação entre as doses de DLS e a adubação mineral demonstra que a produção de matéria seca pelo milho, nos tratamentos sem DLS, com $20 \mathrm{~m}^{3} \mathrm{ha}^{-1}$ e $40 \mathrm{~m}^{3} \mathrm{ha}^{-1}$, foi, estatisticamente, inferior àquela com adubação química, diversamente da dose 


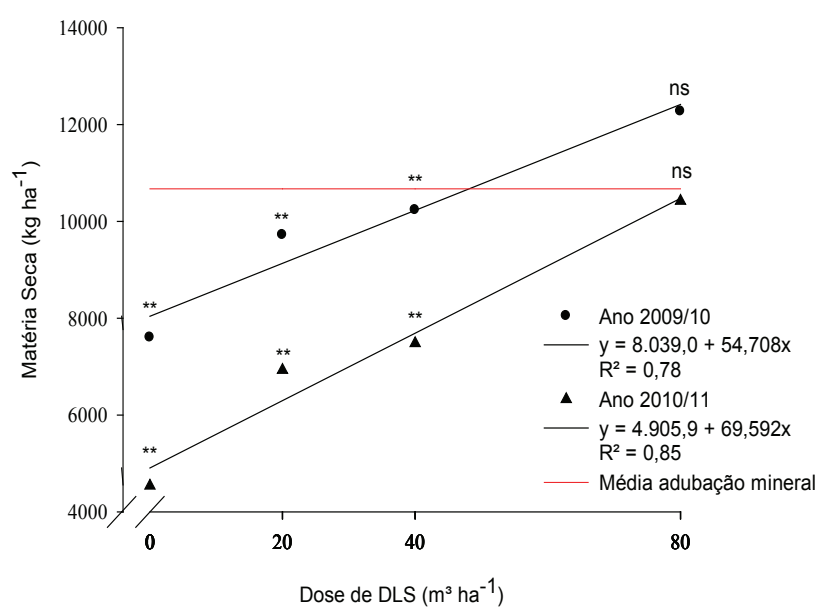

Figura 3. Produção de matéria seca de milho, nos anos agrícolas 2009/2010 e 2010/2011, em função de doses de dejeto líquido de suínos (DLS) e adubação mineral (Taquaruçu do Sul, RS, 2011). ** Diferença significativa entre a adubação mineral e a respectiva dose de DLS; ${ }^{\text {ns }}$ não significativa, por contraste Dunnett $(\mathrm{p}<0,05)$.

de $80 \mathrm{~m}^{3} \mathrm{ha}^{-1}$, na qual a produção de matéria seca foi igual à obtida com adubação mineral (Figura 3).

A produtividade de grãos de milho foi afetada, significativamente, pelos manejos de solo, em função das doses de DLS e da adubação mineral (Tabela 3).

Para o tratamento sem DLS e com aplicação de $20 \mathrm{~m}^{3} \mathrm{ha}^{-1}$, não houve diferença significativa entre os manejos de solo, o que pode estar associado ao fato de o solo da área experimental apresentar teores baixos e muito baixos de matéria orgânica e $\mathrm{P}$, respectivamente, sendo estes fatores limitantes à produção de grãos, em ambos os manejos de solo.

Nas doses de $40 \mathrm{~m}^{3}$ ha $^{-1}$ e $80 \mathrm{~m}^{3} \mathrm{ha}^{-1}$ de DLS e adubação mineral, nas quais foram adicionadas maiores quantidades de nutrientes, a produtividade de milho, no manejo de solo com escarificação, foi, em geral, superior à dos demais manejos. Isto pode ser atribuído a uma possível compactação do solo da área do experimento, onde a escarificação mecânica pode ter rompido esta camada compactada, permitindo melhor desenvolvimento do sistema radicular do milho e aproveitamento dos nutrientes aplicados ao solo via DLS e adubação mineral (Kunz et al. 2013).

Incrementos na produtividade de milho, com a escarificação do solo, também foram observados por Camara \& Klein (2005), Pinheiro et al. (2009) e Secco et al. (2009), sendo que a escarificação reduziu a densidade e aumentou a rugosidade superficial, condutividade hidráulica e taxa de infiltração de água no solo. Desta forma, a escarificação pode trazer resultados benéficos, principalmente em anos com défice hídrico, pelo maior armazenamento de água no solo e por favorecer o desenvolvimento do sistema radicular (Klein \& Camara 2007), podendo incrementar a produtividade de grãos (Nascente et al. 2011).

Com relação às doses de DLS e seu efeito na produtividade de grãos de milho, houve incremento até a maior dose utilizada, com comportamento diferente entre os anos (Figura 4).

No ano agrícola 2009/2010, o aumento na produtividade de grãos foi linear, com incrementos de $62 \%, 134 \%$ e $268 \%$, em relação ao tratamento sem aplicação de DLS, respectivamente para as doses de $20 \mathrm{~m}^{3} \mathrm{ha}^{-1}, 40 \mathrm{~m}^{3} \mathrm{ha}^{-1}$ e $80 \mathrm{~m}^{3} \mathrm{ha}^{-1}$.

Para o ano agrícola 2010/2011, a equação da produtividade foi quadrática, apresentando tendência de estabilização à medida em que se aumentou a dose de DLS. Os incrementos, para o segundo ano agrícola, foram de $57 \%, 151 \%$ e $229 \%$, em relação aos tratamentos sem DLS, respectivamente para as doses de $20 \mathrm{~m}^{3} \mathrm{ha}^{-1}, 40 \mathrm{~m}^{3} \mathrm{ha}^{-1}$ e $80 \mathrm{~m}^{3} \mathrm{ha}^{-1}$.

Quanto à produtividade de grãos de milho por $\mathrm{m}^{3}$ de DLS, verificou-se estabilização e redução

Tabela 3. Produtividade média de grãos de milho, nos anos agrícolas 2009/2010 e 2010/2011, em resposta a doses de dejeto líquido de suínos (DLS) e adubação mineral, em diferentes manejos de solo (Taquaruçu do Sul, RS, 2011).

\begin{tabular}{|c|c|c|c|}
\hline \multirow{2}{*}{ Tratamento $^{1}$} & \multicolumn{3}{|c|}{ Manejo do solo } \\
\hline & Escarificação + gradagem & Escarificação & Plantio direto \\
\hline & & $-\mathrm{kg} \mathrm{ha}^{-1}$ & \\
\hline Sem DLS & $1.481,3 \mathrm{~A}^{1}$ & $2.119,6 \mathrm{~A}$ & $1.808,4 \mathrm{~A}$ \\
\hline $20 \mathrm{~m}^{3} \mathrm{ha}^{-1}$ & $3.093,0 \mathrm{~A}$ & $2.674,9 \mathrm{~A}$ & $2.840,3 \mathrm{~A}$ \\
\hline $40 \mathrm{~m}^{3} \mathrm{ha}^{-1}$ & $3.973,7 \mathrm{~B}$ & $4.883,8 \mathrm{~A}$ & $4.481,8 \mathrm{AB}$ \\
\hline $80 \mathrm{~m}^{3} \mathrm{ha}^{-1}$ & $6.097,0 \mathrm{AB}$ & $6.655,6 \mathrm{~A}$ & $5.750,6 \mathrm{~B}$ \\
\hline Adubação mineral & $7.493,3 \mathrm{~A}$ & $7.141,0 \mathrm{~A}$ & $6.146,8 \mathrm{~B}$ \\
\hline
\end{tabular}

${ }^{1}$ Médias seguidas pela mesma letra, na linha, não diferem entre si, pelo teste Tukey $(\mathrm{p}<0,05)$. 


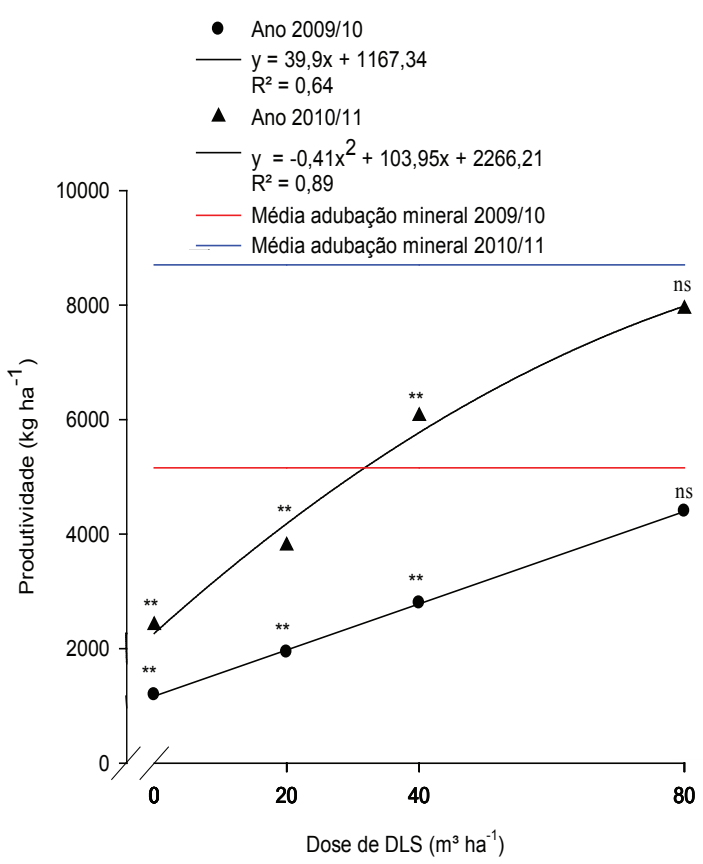

Figura 4. Produtividade média de milho, em função de doses de dejeto líquido de suínos (DLS) e adubação mineral, nos anos agrícolas 2009/2010 e 2010/2011 (Taquaruçu do Sul, RS, 2011). ** Diferença significativa entre a adubação mineral e a respectiva dose de DLS; ${ }^{\text {ns }}$ não significativa, por contraste Dunnett $(\mathrm{p}<0,05)$.

nos incrementos, conforme o aumento das doses, para os dois anos agrícolas, sendo estes valores de $37 \mathrm{~kg} \mathrm{ha}^{-1}, 40 \mathrm{~kg} \mathrm{ha}^{-1}$ e $40 \mathrm{~kg} \mathrm{ha}^{-1}$, para o primeiro ano, e de $70 \mathrm{~kg} \mathrm{ha}^{-1}, 91 \mathrm{~kg} \mathrm{ha}^{-1}$ e $69 \mathrm{~kg} \mathrm{ha}^{-1}$, para o segundo ano, respectivamente para os tratamentos com $20 \mathrm{~m}^{3}$ ha $^{-1}, 40 \mathrm{~m}^{3} \mathrm{ha}^{-1}$ e $80 \mathrm{~m}^{3} \mathrm{ha}^{-1}$.

Os resultados encontrados neste trabalho, com relação à produtividade de grãos de milho, assemelham-se aos obtidos em estudo realizado por Ceretta et al. (2005), no qual a produtividade de grãos de milho aumentou, nos dois anos de cultivo com o uso de DLS, sendo a máxima eficiência técnica encontrada pelos autores com a aplicação de $85 \mathrm{~m}^{3} \mathrm{ha}^{-1}$ de DLS, no primeiro ano do trabalho. No entanto, cabe ressaltar que este valor deve variar em função da composição do DLS, de acordo com cada sistema de produção (Gonçalves Júnior et al. 2008, Vivian et al. 2010).

A comparação entre as doses de DLS e a adubação mineral, para a produção de grãos de milho, permitiu verificar que, nos dois anos do estudo, a dose de $80 \mathrm{~m}^{3} \mathrm{ha}^{-1}$ de DLS foi, estatisticamente, igual à da adubação mineral. Estes resultados corroboram os obtidos por Seidel et al. (2010), que utilizaram doses entre $20 \mathrm{~m}^{3}$ ha-1 e $50 \mathrm{~m}^{3} \mathrm{ha}^{-1}$ de DLS, combinadas ou não com adubação mineral, e verificaram que a aplicação de DLS como adubação de base foi, estatisticamente, igual à da adubação mineral, na produção de grãos de milho, demonstrando a importância do DLS como fonte de nutrientes para o milho.

\section{CONCLUSÕES}

1. A aplicação de dejeto líquido de suínos promoveu incremento na produção de matéria seca da sucessão aveia/milho e na produtividade de grãos de milho.

2. A resposta do milho, para a dose de $80 \mathrm{~m}^{3} \mathrm{ha}^{-1}$, mostrou-se igual à da adubação mineral recomendada para a cultura.

3. O plantio direto favoreceu a produção de matéria seca da aveia preta.

4. Maiores doses de dejeto líquido de suínos e manejos com revolvimento do solo promoveram incrementos na produtividade de grãos de milho.

\section{AGRADECIMENTOS}

Ao Conselho Nacional de Desenvolvimento Científico e Tecnológico (CNPq), pela concessão da bolsa de estudo ao segundo autor.

\section{REFERÊNCIAS}

AITA, C.; PORT, O.; GIACOMINI, S. J. Dinâmica do nitrogênio no solo e produção de fitomassa por plantas de cobertura no outono/inverno com o uso de dejetos de suínos. Revista Brasileira de Ciência do Solo, Viçosa, v. 30, n. 5, p. 901-910, 2006.

AITA, C.; GIACOMINI, S. J. Nitrato no solo com a aplicação de dejetos líquidos de suínos no milho em plantio direto. Revista Brasileira de Ciência do Solo, Viçosa, v. 32, n. 6, p. 2101-2111, 2008.

ASSMANN, J. M. et al. Produção de matéria seca de forragem e acúmulo de nutrientes em pastagem anual de inverno tratada com esterco líquido de suínos. Ciência Rural, Santa Maria, v. 39, n. 8, p. 2408-2416, 2009.

BORGHI, E. et al. Produtividade e qualidade de forragem de milho em função da população de plantas, do sistema de preparo do solo e da adubação. Revista Brasileira de Agrociência, Pelotas, v. 13, n. 4, p. 465-471, 2007. 
CAMARA, R. K.; KLEIN, R. K. Escarificação em plantio direto como técnica de conservação do solo e da água. Revista Brasileira de Ciência do Solo, Viçosa, v. 29, n. 3 , p. 789-796, 2005.

CELA, S.; SANTIVERI, F.; LLOVERAS, J. Residual effects of pig slurry and mineral nitrogen fertilizer on irrigated wheat. European Journal of Agonomy, London, v. 34, n. 4, p. 257-262, 2011.

CERETTA, C. A. et al. Produtividade de grãos de milho, produção de matéria seca e acúmulo de nitrogênio, fósforo e potássio na rotação aveia preta/milho/nabo forrageiro com aplicação de dejeto líquido de suínos. Ciência Rural, Santa Maria, v. 35, n. 6, p. 1287-1295, 2005.

\section{COMISSÃO DE QUÍMICA E FERTILIDADE DE SOLO} (CQFS RS/SC). Manual de adubação e calagem para os Estados do Rio Grande do Sul e Santa Catarina. 10. ed. Porto Alegre: Sociedade Brasileira de Ciência do Solo, 2004.

EMPRESA BRASILEIRA DE PESQUISA AGROPECUÁRIA (Embrapa). Centro Nacional de Pesquisa de Solos. Sistema brasileiro de classificação de solos. 3. ed. Rio de Janeiro: Embrapa, 2013.

GIACOMINI, S. J.; AITA, C. Cama sobreposta e dejetos líquidos de suínos como fonte de nitrogênio ao milho. Revista Brasileira de Ciência do solo, Viçosa, v. 32, n. 1, p. 195-205, 2008.

GIACOMINI, S. J. et al. Aproveitamento pelo milho do nitrogênio amoniacal de dejetos líquidos de suínos em plantio direto e preparo reduzido do solo. Pesquisa Agropecuária Brasileira, Brasília, DF, v. 44, n. 7, p. 761768, 2009.

GONÇALVES JÚNIOR, A. C. et al. Remoção de metais pesados tóxicos cádmio, chumbo e cromo em biofertilizante suíno utilizando macrófita aquática (Eichornia crassipes) como bioindicador. Acta Scientiarum Technology, Maringá, v. 30, n. 1, p. 9-14, 2008.

GONZATTO, G. et al. Volatilização de amônia e emissão de óxido nitroso após aplicação de dejetos líquidos de suínos em solo cultivado com milho. Ciência Rural, Santa Maria, v. 43, n. 9, p. 1590-1596, 2013.

KLEIN, V. A.; CAMARA, R. K. Rendimento da soja e intervalo hídrico ótimo em Latossolo Vermelho sob plantio direto escarificado. Revista Brasileira de Ciência do Solo, Viçosa, v. 31, n. 1, p. 221-227, 2007.

KUNZ, M. et al. Compactação do solo na integração sojapecuária de leite em Latossolo argiloso com semeadura direta e escarificação. Revista Brasileira de Ciência do Solo, Viçosa, v. 37, n. 6, p. 1699-1708, 2013.
MEDEIROS, L. T. et al. Produção e qualidade da forragem de capim-marandu fertirrigada com dejetos líquidos de suínos. Revista Brasileira de Zootecnia, Viçosa, v. 36, n. 2, p. 309-318, 2007.

MOREnO, J. A. Clima do Rio Grande do Sul. Porto Alegre: Secretaria da Agricultura, 1961.

NASCENTE, A. S. et al. Produtividade do arroz de terras altas em função do manejo do solo e da época de aplicação de nitrogênio. Pesquisa Agropecuária Tropical, Goiânia, v. 41, n. 1, p. 60-65, 2011.

PINHEIRO, A.; TEIXEIRA, L. P.; KAUFMANN, V. Capacidade de infiltração de água em solo sob diferentes usos e práticas de manejo agrícola. Journal of Applied Science, Taubaté, v. 4, n. 2, p. 188-199, 2009.

RALISCH, R. et al. Resistência à penetração de um Latossolo Vermelho Amarelo do Cerrado sob diferentes sistemas de manejo. Revista Brasileira de Engenharia Agrícola e Ambiental, Campina Grande, v. 12, n. 4, p. 381384, 2008.

SÁNCHEZ, M.; GONZÁLEZ, J. L. The fertilizer value of pig slurry: I. Values depending on the type of operation. Bioresource Technology, Palencia, v. 96, n. 10, p. 11171123, 2005.

SAS INSTITUTE. Statistical analysis system: SAS/STAT user's guide 8.0. Cary: SAS Institute, 1999.

SECCO, D. et al. Atributos físicos e rendimento de grãos de trigo, soja e milho em dois latossolos compactados e escarificados. Ciência Rural, Santa Maria, v. 39, n. 1, p. 58-64, 2009.

SEIDEL, E. P. et al. Aplicação de dejetos de suínos na cultura do milho cultivado em sistema de plantio direto. Acta Scientiarum Technology, Maringá, v. 32, n. 2, p. 113117, 2010.

TEDESCO, M. J. et al. Análise de solo, plantas e outros materiais. Porto Alegre: UFRS, 1995. (Boletim técnico, 5).

VIVAN, M. et al. Eficiência da interação biodigestor e lagoas de estabilização na remoção de poluentes em dejetos de suínos. Revista Brasileira de Engenharia Agrícola e Ambiental, Campina Grande, v. 14, n. 3, p. 320-325, 2010. 